\title{
Publisher Correction: Stochastic nonlinear dynamics of confined cell migration in two-state systems
}

David B. Brückner (D), Alexandra Fink, Christoph Schreiber, Peter J. F. Röttgermann, Joachim O. Rädler and

Chase P. Broedersz (D)

Correction to: Nature Physics https://doi.org/10.1038/s41567-019-0445-4, published online 4 March 2019.

In the version of this Article originally published online, in the 'Journal peer review information' statement, the reviewer Henrik Flyvbjerg was mistakenly not included; the statement has now been updated accordingly.

Published online: 18 March 2019

https://doi.org/10.1038/s41567-019-0493-9 